\title{
Strongyloidiasis Presenting as Yellowish Nodules in Colonoscopy of an Immunocompetent Patient
}

\author{
Hannah Ra ${ }^{1}$, Jun-Won Chung ${ }^{1}$, Dong Hae Chung ${ }^{2}$, Jung Ho Kim${ }^{1}$, Yoon Jae Kim${ }^{1}$, Kyoung Oh Kim${ }^{1}$, Kwang An Kwon ${ }^{1}$ and \\ Dong Kyun Park ${ }^{1}$ \\ Department of ${ }^{1}$ Internal Medicine, ${ }^{2}$ Pathology, Gachon University of Medical and Science, Incheon, Korea
}

Strongyloides stercoralis is endemic to tropical and subtropical regions, and infections are usually asymptomatic. However, immunocompromised patients, such as those receiving immunosuppressive therapy, high-dose steroids, or chemotherapy, can develop fatal hyperinfections. An 84-year-old man without any symptoms was diagnosed with strongyloidiasis during a regular screening colonoscopy. His medical history only involved a gastric endoscopic submucosal dissection for early gastric cancer 6 months previously. Few cases have been published about asymptomatic strongyloidiasis diagnosed in an immunocompetent host via endoscopic mucosal resection with characteristic colonoscopic findings. We report a case of colon-involved asymptomatic strongyloidiasis with specific colonic findings of yellowish-white nodules. This finding may be an important marker of S. stercoralis infection, which could prevent hyperinfections. Clin Endosc 2019;52:80-82

Key Words: Colonoscopy; Endoscopic mucosal resection; Strongyloidiasis

\section{INTRODUCTION}

Strongyloides stercoralis infections are endemic in tropical and some temperate areas where poor hygiene promotes transmission. ${ }^{1,2}$ In immunocompetent patients, strongyloidiasis is usually either asymptomatic or causes mild gastrointestinal symptoms, such as dyspepsia, nausea, and vomiting. However, it can lead to an overwhelming hyperinfection syndrome caused by autoinfection, or a disseminated form of strongyloidiasis triggered by acquired or iatrogenic immunosuppression with severe sepsis. ${ }^{3,4}$ Corticosteroid use, chemotherapy, a cancerous state, and human immunodeficiency virus (HIV) infection are factors involved in hyperinfection syndrome. ${ }^{5}$

Received: May 5, 2018 Revised: July 3, 2018

Accepted: July 30, 2018

Correspondence: Jun-Won Chung

Department of Internal medicine, Gachon University, Gil Medical Center,

21 Namdong-daero 774 beon-gil, Namdong-gu, Incheon 21565, Korea

Tel: +82-32-460-3778, Fax: +82-32-460-3778, E-mail: drgreen@gilhospital.com

ORCID: https://orcid.org/0000-0002-0869-7661

(c) This is an Open Access article distributed under the terms of the Creative Commons Attribution Non-Commercial License (http://creativecommons.org/ licenses/by-nc/3.0) which permits unrestricted non-commercial use, distribution, and reproduction in any medium, provided the original work is properly cited.
S. stercoralis has two different reproductive cycles: an asexual cycle that occurs inside humans, particularly in the duodenum and small intestine, and sexual reproduction in the soil. The parasite has the ability to multiply inside the host while transforming the rhabditiform larvae into the infective filariform stage when environmental conditions change. ${ }^{6}$

The upper endoscopic features of strongyloidiasis have been reported. ${ }^{7}$ However, colonoscopic-specific findings have not, other than a broad range of features. ${ }^{8}$ Herein, we report a case of strongyloidiasis with no symptoms in an immunocompetent host that was discovered incidentally as a result of a specific colonic finding.

\section{CASE REPORT}

An 84-year-old man presented to our hospital for an upper endoscopy due to dyspepsia. Esophagogastroduodenoscopy (EGD) detected erythematous gastric mucosa with an irregular margin, and biopsy revealed early gastric cancer. He therefore underwent endoscopic submucosal dissection (ESD). Approximately 6 months later, with no symptoms, he 

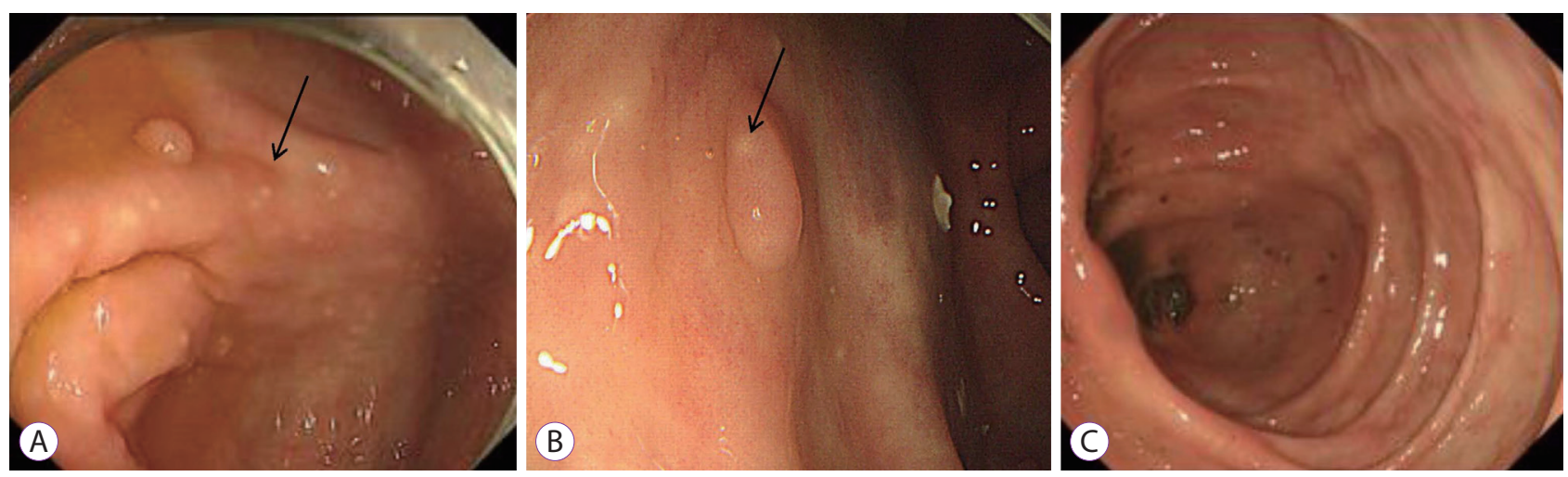

Fig. 1. Colonoscopic findings showing (A) multiple yellowish nodules and polyps in the ascending colon, and (B) yellowish nodules were found on the top of a polyp (before treatment). (C) The nodules disappeared after treatment.

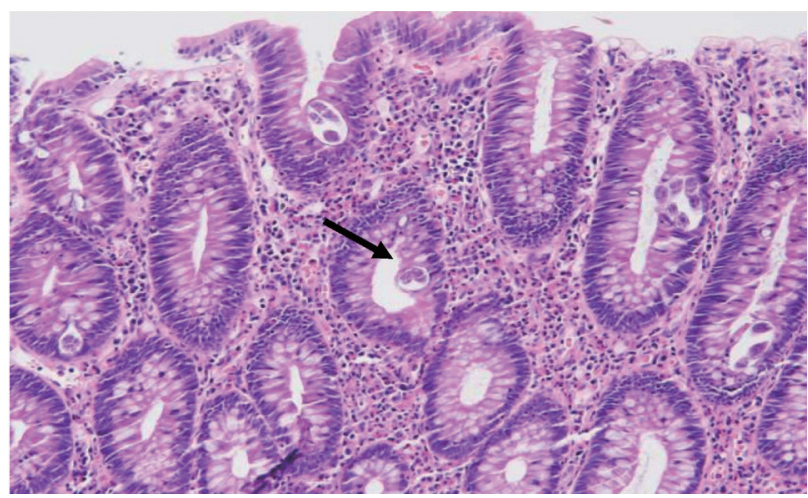

Fig. 2. Histological findings. Numerous cross-sectioned filariform larvae (arrow) with distortion of crypts and diffuse eosinophilic infiltration are visible in the lamina propria of the colon (hematoxylin and eosin, $\times 200$ ).

attended the hospital again for a follow-up and also requested a colonoscopy because he had no colonoscopy experience. His physical examination was normal except mild conjunctive anemia. No abdominal pain (direct or rebound tenderness) was detected.

The results of peripheral blood tests were as follows: hemoglobin $10.0 \mathrm{~g} / \mathrm{dL}$, hematocrit $33.2 \%$, and white blood cell count $9,530 / \mathrm{mm}^{3}$ (neutrophils $41.2 \%$, lymphocytes $26.3 \%$, and eosinophils $25.4 \%$ ). The total eosinophil count was $2,420.62 / \mathrm{mm}^{3}$ (normal range of total eosinophil $40-500 / \mathrm{mm}^{3}$ [1\%-6\%]), and the platelet count was $261,000 / \mathrm{mm}^{3}$. Other data were as follows: blood urea nitrogen $29.9 \mathrm{mg} / \mathrm{dL}$, creatinine $1.0 \mathrm{mg} / \mathrm{dL}$, total protein $6.9 \mathrm{~g} / \mathrm{dL}$, albumin $4.0 \mathrm{~g} / \mathrm{dL}$, total bilirubin 0.7 $\mathrm{mg} / \mathrm{dL}$, aspartate aminotransferase $18 \mathrm{IU} / \mathrm{L}$, alanine aminotransferase $10 \mathrm{IU} / \mathrm{L}$, sodium $138 \mathrm{mEq} / \mathrm{L}$, potassium $4.4 \mathrm{mEq} / \mathrm{L}$, calcium $8.9 \mathrm{mg} / \mathrm{dL}$, prothrombin time $12.0 \mathrm{~s}$, and activated partial thrombin time $33.1 \mathrm{~s}$. Urinalysis was normal. He had no history of receiving glucocorticoid therapy and was negative for HIV. There was no evidence of recurrence at the ESD site, and no metastasis to lymph nodes or other organs was detected in an abdominal computed tomography scan.
Diffuse atrophic gastritis was observed during the EGD, and an ESD scar was seen at the lesser curvature side of the lower body; the duodenum was normal. Edema of the right colon (especially the ascending colon) wall with multiple $10-20 \mathrm{~mm}$ polyps and $0.5-1 \mathrm{~mm}$ diffuse yellowish-white nodules were seen during the colonoscopy in the ascending colon. Twenty-four colonic polyp specimens were removed by endoscopic mucosal resection or polypectomy through the ascending colon (Fig. 1). Yellowish nodules were found on the top of the polyps, and polypectomy was performed. A pathological examination revealed filariform larvae and eosinophilic infiltration in the mucosal layer of the ascending colon (Fig. 2). After taking $400 \mathrm{mg}$ albendazole for 3 days, the $S$. stercoralis larvae and yellowish nodules were not seen at a year follow-up colonoscopic random biopsy, and his eosinophil count returned to the normal range as $661.8 / \mathrm{mm}^{3}(6 \%)$.

\section{DISCUSSION}

Strongyloidiasis can have many colonoscopic features, such as loss of the vascular pattern, erythema, and mild edema to ulcers, erosions, and yellowish-white nodules. ${ }^{8}$ If $S$. stercoralis infects the colonic mucosa, eosinophils will collect and form granulation tissue on the mucosal surface. Dense eosinophilic infiltrations may appear macroscopically as yellowish-white nodules. These nodules are a strong indicator of strongyloidiasis colonic involvement compared to other nonspecific characteristics. At a single center on an endemic island of Japan, a study found that colonoscopic findings, such as yellowish-white nodules, and biopsies could be useful to diagnose asymptomatic strongyloidiasis. ${ }^{9}$ To the best of our knowledge, this is the first case report of yellowish-white nodules during a colonoscopy in a case of strongyloidiasis in Korea.

S. stercoralis can infect both immunocompromised and immunocompetent hosts. Most cases of strongyloidiasis have 
mild symptoms or are asymptomatic (30\%), but hyperinfection can be very severe and results in death in $60 \%$ of cases. ${ }^{10}$ This infection involves different organs in the host. For example, S. stercoralis present in the gastrointestinal tract can cause vomiting, diarrhea with abdominal pain, and hyponatremia, even in young men. ${ }^{11}$ It can produce mild upper respiratory symptoms, cough, sputum or diffuse alveolar hemorrhage, and severe hypoxemia after infecting the lung. ${ }^{12}$ Chronic anemia can also result from strongyloidiasis-related disease in hepatic cirrhosis patients with severe alcoholism. ${ }^{6}$

Diagnosis of $S$. stercoralis hyperinfection can be difficult to confirm. In a previous study, the Kato-Katz technique, stool microscopy, the Baermann technique, and Koga agar plate cultures were used to detect $S$. stercoralis infection; however, these methods are inadequate because of low sensitivity. Serological testing has higher sensitivity and is useful for follow-up diagnosis. ${ }^{13}$ The luciferase immunoprecipitation system technique and enzyme-linked immunosorbent assay (ELISA) coproantigen detection tests are promising assays with $100 \%$ specificity, but they require further evaluation to confirm their efficacy in predicting infection. ${ }^{14}$ Only $2 \%$ of S. stercoralis infections are detected by an EGD. ${ }^{15}$ Eggs and adult worms have been seen in the duodenum, and larvae have been observed in the small intestine. ${ }^{8}$ Capsule endoscopy may be useful to detect larvae in the small intestine, but it is expensive. In the present case, a stool examination and ELISA were not used for the initial diagnosis; the patient showed no symptoms, so parasitic infection was not suspected at that time. Statistically, $25 \%$ of infected patients produce a negative result for these tests. ${ }^{16}$ We found $S$. stercoralis filariform larvae in histological sections from a colonoscopic biopsy (Fig. 2). A previous case report detailed $S$. stercoralis infection in an immunocompromised host with a risk factor of high-dose steroids, which was diagnosed by colonoscopic biopsy of multiple polyps in diffuse pancolitis. ${ }^{17}$ A case of pancolitis with strongyloidiasis has been reported in an immunocompetent patient. ${ }^{9}$ Strongyloidiasis has also been diagnosed by capsule endoscopy in an immunocompetent host. However, in those cases, both patients had abdominal pain and severe diarrhea, whereas our patient was asymptomatic. ${ }^{5}$

The strongyloidiasis treatment of choice has been thiabendazole $25 \mathrm{mg} / \mathrm{kg} / 12 \mathrm{~h}$ for 3 consecutive days; however, a single dose of $15 \mathrm{mg}$ ivermectin is currently being used because of better tolerability and similar efficacy. ${ }^{18}$ Our patient received $400 \mathrm{mg}$ albendazole orally for 3 days and was cured without complications.

In conclusion, we report a case of $S$. stercoralis infection involving the ascending colon in an immunocompetent host, with specific yellowish-white nodules. If a patient has yellowish nodules in the colon, a biopsy should be performed to detect strongyloidiasis and prevent a hyperinfection.

Conflicts of Interest

The authors have no financial conflicts of interest.

\section{REFERENCES}

1. Buonfrate D, Baldissera M, Abrescia F, et al. Epidemiology of Strongyloides stercoralis in northern Italy: results of a multicentre case-control study, February 2013 to July 2014. Euro Surveill 2016;21.

2. Khieu V, Schär F, Forrer A, et al. High prevalence and spatial distribution of Strongyloides stercoralis in rural Cambodia. PLoS Negl Trop Dis 2014;8:e2854.

3. Yung EE, Lee CM, Boys J, Grabo DJ, Buxbaum JL, Chandrasoma PT. Strongyloidiasis hyperinfection in a patient with a history of systemic lupus erythematosus. Am J Trop Med Hyg 2014;91:806-809.

4. Greaves D, Coggle S, Pollard C, Aliyu SH, Moore EM. Strongyloides stercoralis infection. BMJ 2013;347:f4610.

5. Xouris D, Vafiadis-Zoumbulis I, Papaxoinis K, et al. Possible Strongyloides stercoralis infection diagnosed by videocapsule endoscopy in an immunocompetent patient with devastating diarrhea. Ann Gastroenterol 2012;25:268-270

6. Teixeira MC, Inês EJ, Pacheco FT, et al. Asymptomatic Strongyloides stercoralis hyperinfection in an alcoholic patient with intense anemia. J Parasitol 2010;96:833-835.

7. Kishimoto K, Hokama A, Hirata T, et al. Endoscopic and histopathological study on the duodenum of Strongyloides stercoralis hyperinfection. World J Gastroenterol 2008;14:1768-1773.

8. Thompson BF, Fry LC, Wells CD, et al. The spectrum of GI strongyloidiasis: an endoscopic-pathologic study. Gastrointest Endosc 2004;59:906910.

9. Minematsu H, Hokama A, Makishi T, Arakaki K, Kinjo F, Fujita J. Colonoscopic findings and pathologic characteristics of Strongyloides colitis: a case series. Digestion 2011;83:210-214.

10. Sridhara S, Simon N, Raghuraman U, Crowson N, Aggarwal V. Strongyloides stercoralis pancolitis in an immunocompetent patient. Gastrointest Endosc 2008;68:196-199.

11. Mutreja D, Sivasami K, Tewari V, Nandi B, Nair GL, Patil SD. A 36-yearold man with vomiting, pain abdomen, significant weight loss, hyponatremia, and hypoglycemia. Indian J Pathol Microbiol 2015;58:500-505.

12. El-Sameed YA, Beejay N, Al Maashari R. Diffuse alveolar haemorrhage and severe hypoxemia from Strongyloides stercoralis hyperinfection syndrome. Clin Respir J 2015;9:489-492.

13. Salvador F, Sulleiro E, Sánchez-Montalvá A, et al. Usefulness of Strongyloides stercoralis serology in the management of patients with eosinophilia. Am J Trop Med Hyg 2014;90:830-834.

14. Buonfrate D, Formenti F, Perandin F, Bisoffi Z. Novel approaches to the diagnosis of Strongyloides stercoralis infection. Clin Microbiol Infect 2015;21:543-552.

15. Dias C, Landaeta J, Armas V. Diagnostic endoscopy of intestinal Strongyloidiasis in an immunocompetent patient by single balloon enteroscopy. Advanced Research in Gastroenterology and Hepatology 2018;8:555741.

16. Sato Y, Kobayashi J, Toma H, Shiroma Y. Efficacy of stool examination for detection of Strongyloides infection. Am J Trop Med Hyg 1995;53:248-250.

17. Nam SC, Han MH, Kim YS, Kum YS, Suh IS, Bae HI. Two cases of Strongyloidiasis diagnosed by colonoscopic biopsy. Korean J Pathol 2007;41:343-346.

18. Khieu V, Schär F, Marti $\mathrm{H}$, et al. Diagnosis, treatment and risk factors of Strongyloides stercoralis in schoolchildren in Cambodia. PLoS Negl Trop Dis 2013;7:e2035. 